\title{
Acoustic behaviors in Hawaiian coral reef fish communities
}

\author{
Timothy C. Tricas ${ }^{1,2, *}$, Kelly S. Boyle ${ }^{1,2,3}$ \\ ${ }^{1}$ Department of Biology (formerly Zoology), 2538 The Mall, Edmondson Hall, University of Hawai'i at Manoa, \\ Honolulu, HI 96822, USA \\ ${ }^{2}$ Hawai'i Institute of Marine Biology, 46-007 Lilipuna Rd., Kane'ohe, HI 96744, USA \\ ${ }^{3}$ Present address: Département d'Ecologie et de Gestion de la Biodiversité, Muséum National d'Histoire Naturelle, \\ 57 rue Cuvier, Case postale 55, 75231, Paris Cedex 5, France
}

\begin{abstract}
Coral reef fish communities often include hundreds of sympatric species which are of great interest to reef conservation and fisheries managers. Longterm acoustic monitoring of fish sounds can be used to infer periodic reproductive activity and changes in population abundance. However, limited records of sound production by coral reef species have precluded the application of acoustic monitoring at the population or community levels. We used rebreather and digital acoustic/video techniques to produce a sound library for fishes on coral reefs of west Hawai'i Island, HI, USA. We documented 85 sounds produced by 45 (47\%) of the 96 resident species that were associated with agonistic interactions and resource defense, reproduction, nest defense, feeding, and vigilance behaviors. Most nonfeeding sounds consisted of single or trains of pulse events $<100 \mathrm{~ms}$ long that were distributed across a spectrum of $<100$ to $1000 \mathrm{~Hz}$ with the majority of peak frequencies between 100 and $300 \mathrm{~Hz}$. Agonistic sounds created during competitive interactions over food, space, or nest brood resources were identified for damselfishes, surgeonfishes, butterflyfishes, and triggerfishes, among others. Reproductive sounds associated with courtship, spawning, or nest defense were produced by damselfishes, goatfishes, butterflyfishes, parrotfishes, and surgeonfishes, as well as wrasses and Moorish idols. The distinct adventitious feeding sounds recorded for some parrotfishes and triggerfishes occurred in a higher frequency band $(2-6 \mathrm{kHz})$ and may be useful indicators of feeding activity and rates of reef bioerosion. This is the first study to characterize the species-specific behavior soundscape that can be applied to acoustic monitoring of a coral reef fish community.
\end{abstract}

KEY WORDS: Bioacoustics - Rebreather - Reef fish • Sound production $\cdot$ Fish behavior $\cdot$ Coral reef

Resale or republication not permitted without written consent of the publisher

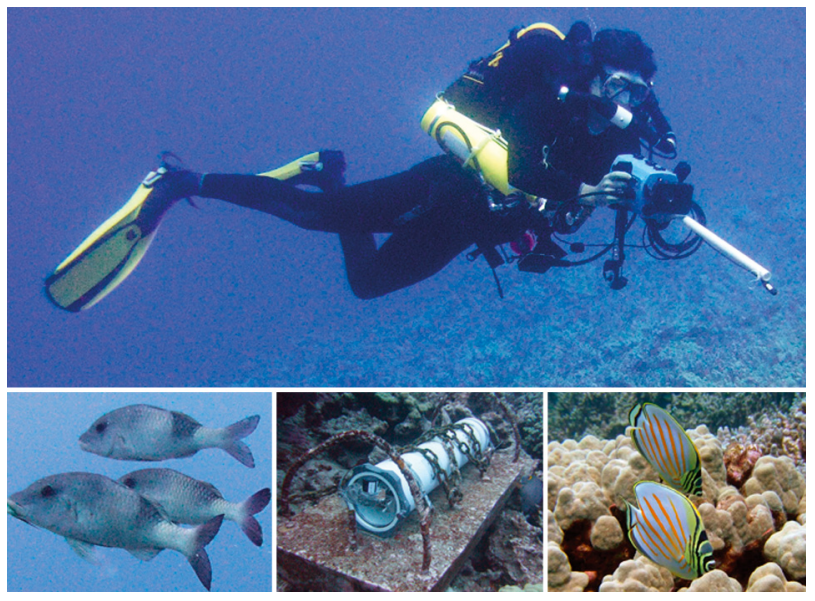

Rebreather divers record sounds produced by coral reef fish during resource defense, reproduction, predator avoidance and feeding for acoustic monitoring of population activities.

Images: Timothy C. Tricas and Kelly S. Boyle

\section{INTRODUCTION}

Coral reef fish communities include sympatric populations of hundreds of species that are concentrated in small geographic areas (Allen \& Werner 2002, Bellwood \& Wainwright 2002). Fish acoustic behaviors are a prominent feature of coral reef environments and provide a potential tool for monitoring and management of fish populations. Many fish produce sounds during agonistic interactions with competitors, responses to predators or threats, and during courtship and spawning (reviewed by Fine et al. 1977, Myrberg 1981). Passive acoustic recordings of 
such species-specific sounds can provide valuable information on the onset, duration, and periodicity of reproductive activities and changes in abundance of local fish populations (Rountree et al. 2003a,b, 2006, Luczkovich et al. 2008). However, despite the many thousands of fish species known to inhabit coral reefs worldwide, sound production is currently described (or hypothesized to exist) for fewer than 300 species, which represents a great underestimate (Lobel et al. 2010). Furthermore, the majority of coral reef fish sounds are anecdotal, qualitative, and lack information on sound waveforms with few records taken from sympatric populations (e.g. Steinberg et al. 1965, Bright 1972). Thus, much work is needed to adequately characterize sonic species, sound repertoires, acoustic features, and behavioral contexts that contribute to the soundscape of coral reef fish communities.

The application of sound libraries to passive acoustic monitoring of fish communities was previously limited by several factors. In many cases, the bioacoustic capabilities of marine species are only partially characterized, and the identities of sonic species are often inferred, misidentified, or unknown (e.g. Steinberg et al. 1962, McCauley \& Cato 2000, Sprague \& Luczkovich 2001, Mann \& Jarvis 2004, Anderson et al. 2008). For many coral reef species, the behavioral context of specific sounds in wild populations is often unknown or incomplete (Fish \& Mowbray 1970, Myrberg \& Fuiman 2002, Lobel et al. 2010). One important feature of fish sounds is their low-frequency spectrum $(<50 \mathrm{~Hz}$ to several $\mathrm{kHz}$ ) and competing background noise from wind, waves, and other sources in this frequency band (Wenz 1962, Cato 1980). The direct observation of bioacoustic behaviors by scuba divers is limited by the exhalant bubble noise and limited bottom time. This affords a great advantage for the use of rebreather life-support systems that produce no exhalant bubble noise and provide extended bottom time (Bright 1972, Lobel 2005, Radford et al. 2005) and also for recent digital video/audio recording equipment and analysis software. These technological enhancements now facilitate the creation of species-specific and context-specific acoustic libraries for coral reef fish communities.

More than 600 species of marine fishes inhabit the inshore and reef areas of Hawai'i, HI, USA (Randall 2007), but details of sound production (waveforms, intensity, frequency spectra) are reported for only a few species: 2 soldierfish Myripristis spp. (Salmon 1967); 2 bigeyes Priacanthus spp. (Salmon \& Winn 1966); 3 damselfishes (Lobel \& Mann 1995, Mann \&
Lobel 1998, Lobel \& Kerr 1999, Maruska et al. 2007), 1 trunkfish (Lobel 1996), 2 wrasses (Boyle \& Cox 2009), 3 butterflyfishes (Tricas et al. 2006, Boyle \& Tricas 2010, 2011), and 1 triggerfish (Salmon et al. 1968). The purpose of this study was to develop an acoustic library of the acoustic behavior of fish species on shallow Hawaiian coral reefs for future use in the interpretation of long-term passive acoustic monitoring data. We used closed-circuit rebreathers to closely approach visually identified species and record sound production in synchrony with their natural behavior. Results show that approximately half of the observed species produce sound in biologically relevant contexts that may be used for identification of social interactions, reproduction, and activity patterns of species in Hawaiian coral reef fish communities.

\section{MATERIALS AND METHODS}

\section{Study locations}

Acoustic behaviors of fish were recorded at Puako Reef on the island of Hawai'i $\left(19.93^{\circ} \mathrm{N}, 155.86^{\circ} \mathrm{W}\right)$ during the spring and summer of 2008 and 2009. This fish management area is characterized by large fields of hard corals that slope to a reef edge at about $15 \mathrm{~m}$ and extend steeply to a sand interface at about $30 \mathrm{~m}$. Many species engage in feeding and social interactions in the water column, near the reef surface, on sand patches, and in caves. Large aggregations of fishes were observed in periodic broadcast spawning activities along the reef edge and deeper slope areas. We also obtained some fish sounds at Papawai Bay in Kona, Hawai'i $\left(19.64^{\circ} \mathrm{N}, 156.02^{\circ} \mathrm{W}\right)$, and the outer reefs of Kaneohe Bay and Honolulu on the island of Oahu.

\section{Dives and data recording}

Divers used Evolution (Ambient Pressure Diving) closed-circuit rebreathers that do not release exhaust bubbles that interfere with acoustic recordings, extend bottom time up to $3 \mathrm{~h}$, and allow very close approach to fish. Most dives were conducted at 8 to $40 \mathrm{~m}$ depth with 1 decompression excursion to rocky outcroppings at $80 \mathrm{~m}$. Acoustic behaviors were recorded with digital video cameras (Sony TRV-950 and Canon Optura) in Amphibico underwater housings equipped with an external hydrophone (HTI min96 High-Tech) that recorded coincident 
sounds on 1 audio channel (48 $\mathrm{kHz}$ sample rate, 20-24000 Hz audio band pass). Dives were conducted between 09:00 and 19:30 h and were often scheduled to observe spawning behaviors in the afternoon, dusk, or on outgoing tides. We evoked aggressive sounds from the normally shy coralfeeding blue-eye damselfish Plectroglyphidodon johnstonianus by placement of a coral-feeding multiband butterflyfish Chaetodon multicinctus within a glass bottle near the territory. The animal use protocol was approved by the University of Hawai'i Institutional Animal Care and Use Committee.

\section{Video and acoustic analyses}

Digital video recordings were imported to a computer in the lab with Windows Movie Maker and saved as an uncompressed AVI file. The entire video and audio recordings were then pre-screened individually by at least 2 reviewers, who logged the times of acoustic events and behavioral context for identified species into a spreadsheet. Discrepancies among these observations of sound production were reviewed and discussed by 2 or more individuals and either collectively accepted as a fish sound or discarded. In cases where fish sounds were not associated with overt body motions, multiple sound events were required to classify a species as acoustically active. Audio was extracted from the video with Cool Edit Pro 2.0 or Adobe Audition and saved in an uncompressed WAV format. When present, camera hum noise was notch filtered at $149.8 \mathrm{~Hz}$ at $\sim 100 \mathrm{~dB}$ attenuation. The associated sound waveform was visually inspected, the duration above background noise measured, and the sound waveform saved. Spectrograms showed that the acoustic energy for

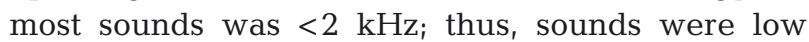
pass filtered in the 'high quality' setting and downsampled to $4 \mathrm{kHz}$. Feeding and social sounds that showed higher spectra were analyzed at the original $48 \mathrm{kHz}$ sampling rate.

Many sounds were emitted as a single continuous waveform (e.g. pulse, growl, blended pulse series that occurred without separation by non-acoustic intervals), whereas others consisted of a series of non-continuous acoustic events (e.g. pulse train, discrete blended pulse events separated by brief nonacoustic intervals). In order to characterize the temporal features of interrupted sounds, we defined a sound type as either (1) a single independent sound event that is separated from subsequent sound events by inter-pulse intervals $\geq 0.5 \mathrm{~s}$, or (2) a sound event train that consisted of a series of sound events (such as single pulses in series or growls with short silent intervals between portions of the overall sound) separated by inter-event intervals $<0.5 \mathrm{~s}$. For sound event trains (most commonly pulse trains), the total number of separate wave events (events or pulses $\operatorname{train}^{-1}$ ) was first enumerated. The onset and offset times of the first 4 events (or the entire train if $\leq 4$ wave events) were then measured for calculation of (1) mean event duration, (2) event train segment duration (for entire trains with 2 to 4 events or the first 4 events in longer trains), (3) event rate $\mathrm{s}^{-1}$, and (4) mean inter-event interval.

Previously unreported sounds were first assigned a descriptive name type based primarily on its acoustic features (e.g. pulse, high-frequency pulse, blended pulse, half-pulse) in order to avoid onomatopoeias and anthropomorphic interpretations that have added to the great non-uniformity of sound nomenclature in the literature as reviewed by Lobel et al. (2010). We secondarily assigned a behavioral descriptor to some sounds that were produced in clear behavioral contexts (e.g. spawning pulse, courtship pulse) especially when there was overlap in acoustic features of sounds within a species (e.g. courtship and spawning pulses in yellow tang Zebrasoma flavescens). The high-frequency broadband sounds produced during feeding by some parrotfishes and triggerfishes were always associated with a scraping behavior of the jaws on the food substrate and were named based purely on the associated 'scrape' behavior. We also assigned sound names in accordance with previously reported sounds for Hawaiian species when possible, and to new and presumed homologous sounds produced by related species (e.g. several pomacentrids and holocentrids).

Relative intensity (the intensity of a sound event relative to background noise), power spectra (the relative power of different frequencies within a single sound event), and spectrograms (the temporal distribution of frequency spectra across the duration of a sound event) were calculated from sound waveforms with custom Matlab 7.0 scripts. Sound power spectra were determined from 1024-point fast Fourier transforms with a Hanning window of 0-padded sounds. Peak frequency (frequency with the highest intensity) and the minimum, maximum, median, and quartiles of all frequencies $\leq 10$ and $\leq 6 \mathrm{~dB}$ intensity of the peak frequency were determined from power spectra data.

Mean and standard error were determined for each acoustic character from averages of each individual (if more than a single sound was recorded from a single fish) and then averaged for individuals of a spe- 
cies. In some cases, sounds were recorded among a group of individuals in small shoals/schools for which it was not possible to determine the vocalizing individual. In such cases, we treated 1 sound recorded from each encountered group as an independent observation to avoid pseudoreplication. Statistical comparisons were made for the acoustic features of sounds produced among some species and behavior categories. Parametric samples were tested for differences with 2 -sample $t$-tests. In many cases, sound duration, peak frequency, or bandwidth samples did not meet the assumptions of normality or homoscedasticity and thus were tested for differences with the non-parametric Mann-Whitney test. We describe the relationship between sound event duration and peak frequency among the observed acoustic species in 13 families with an inverse polynomial regression model. Statistical tests were performed using SigmaPlot v.11.0 and 12.5.

\section{RESULTS}

Rebreather divers logged approximately $180 \mathrm{~h}$ during daylight and dusk hours and identified 96 teleost species (24 families) in the study area at the Puako and Papawai Hawai'i reef sites (see Table S1 in the Supplement; www.int-res.com/articles/suppl/m511 p001_supp.pdf). Analysis of $22 \mathrm{~h}$ of video/audio recordings showed that 45 species $(47 \%)$ in 12 families $(50 \%)$ produced 85 sound types (Table S2 in the Supplement) in several behavioral contexts (Fig. 1). Below we report the characteristics of sounds collated in behavioral categories by family.

\section{Agonistic behaviors - aggression and defense}

Nearly half $(39=45 \%)$ of the documented acoustic behaviors were recorded from 24 species during agonistic (aggressive-submissive) interactions that involved the defense of feeding resources or nest sites, chases and retreats during other social interactions, or interactions with potential predators (Fig. 1, Table S2).

Groupers (Serranidae). The peacock grouper Cephalopholis argus, which occurred at depths of approximately 5 to $25 \mathrm{~m}$, produced loud, low peak frequency $(104 \mathrm{~Hz})$ pulse sounds and trains during agonistic interactions with conspecifics (Fig. 2A).

Butterflyfishes (Chaetodontidae). Pulsed agonistic sounds were recorded for 5 of 6 acoustic butterflyfishes. The coral-feeding multiband butterflyfish

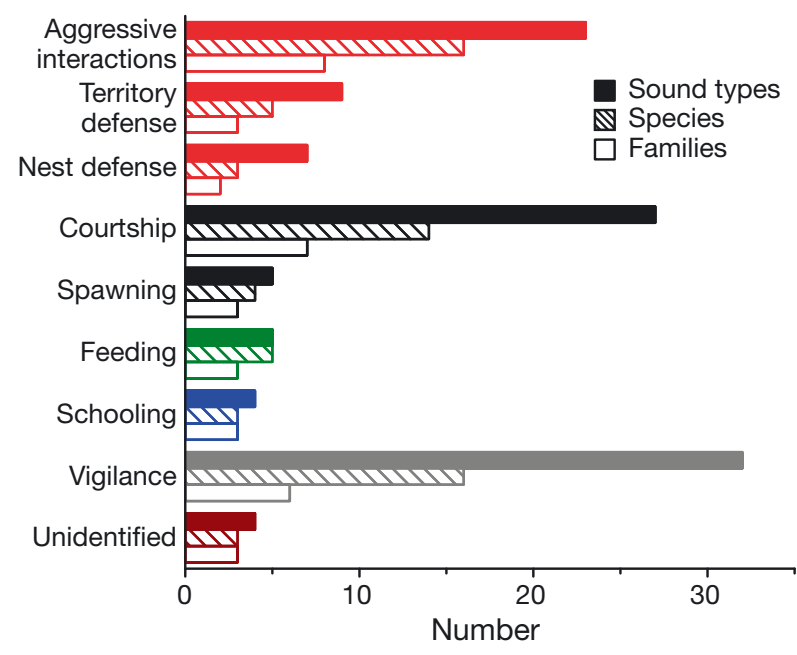

Fig. 1. Behavioral contexts of 85 sound types recorded from 45 species of Hawaiian coral reef fishes. Data are shown for the total number of sounds produced by all species (solid bars), number of species that produced sound associated with a behavior category (hatched bars), and number of fish families the produced sound associated with a behavior category (open bars). Fish sound categories are agonistic behaviors separated into aggressive interactions among individuals and defense of territories or nests (red bars), reproductive interactions separated into courtship and spawning behaviors (black), feeding (green), schooling (blue), vigilance (gray), and unidentified behavioral contexts (burgundy). Several sound types were produced in multiple behavior categories

Chaetodon multicinctus and the ornate butterflyfish C. ornatissimus produced brief pulse sounds 36 to $56 \mathrm{~ms}$ in duration with average peak frequency between 184 and $346 \mathrm{~Hz}$ during agonistic encounters with conspecifics and reproductive activities (described below) (Table S2, Fig. 2B). A unique pulse sound of very brief duration $(7 \mathrm{~ms})$ and the highest high peak frequency $(3609 \mathrm{~Hz})$ recorded in this study was produced by the blacklip butterflyfish C. kleinii during interactions with conspecifics. We also recorded pulse sounds during conspecific agonistic interactions in the pyramid butterflyfish Hemitaurichthys polylepis, but these aggressive sounds were more frequently associated with disturbance and reproductive behaviors (described below).

Damselfishes (Pomacentridae). Five damselfish species produced sounds associated with agonistic interactions among conspecifics or during defense of egg nests (Table S2). Three sound types were produced by males of both the Hawaiian sergeant Abudefduf abdominalis and the Indo-Pacific sergeant $A$. vaigiensis that establish breeding (sometimes heterospecific) colonies. Two sounds produced during agonistic encounters with conspecific and heterospecific individuals were the aggressive short 


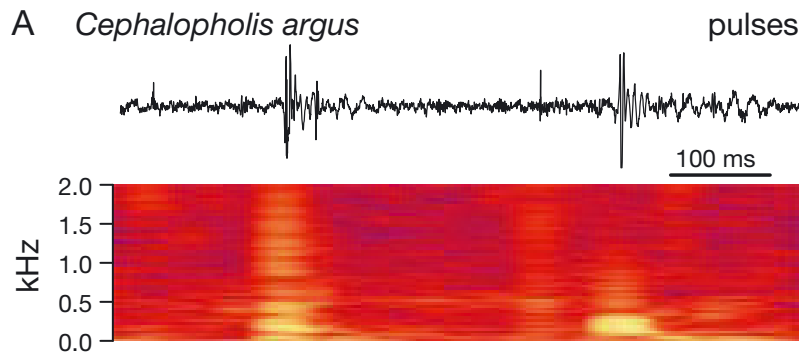

B Chaetodon multicinctus

pulse

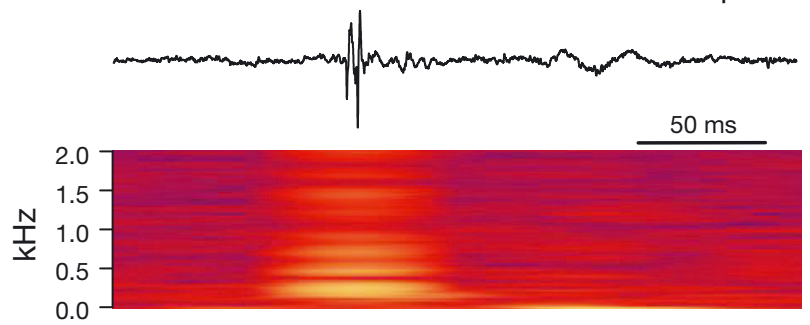

C Abudefduf vaigiensis

high-frequency pulse

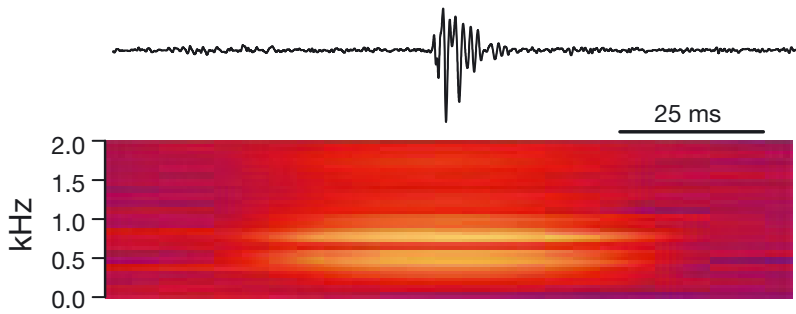

D Plectroglyphidodon johnstonianus

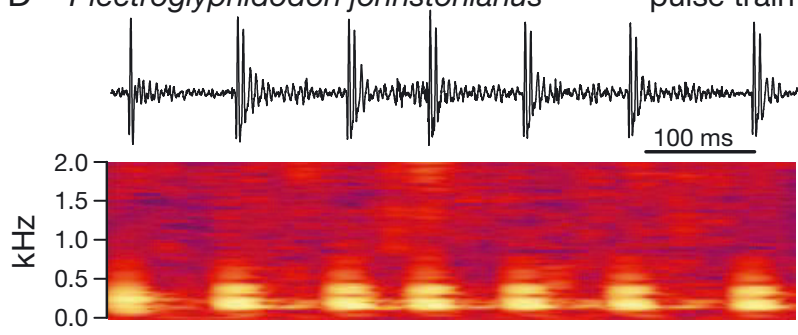

E Plectroglyphidodon johnstonianus
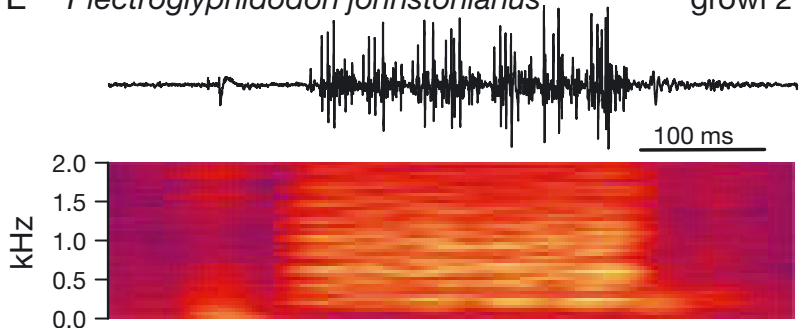

F Stegastes marginatus

half pulse train

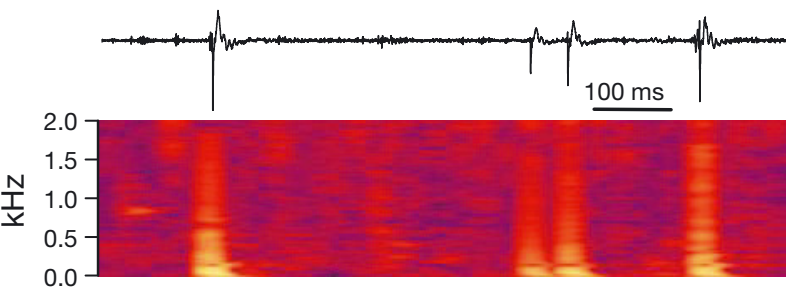

G Melichthys niger
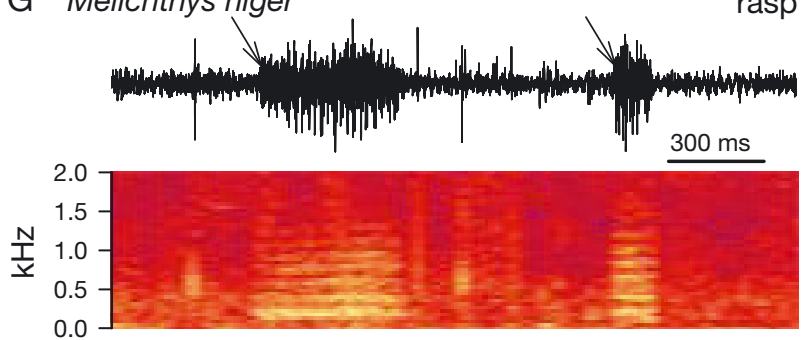

H Sufflamen bursa

pulse train
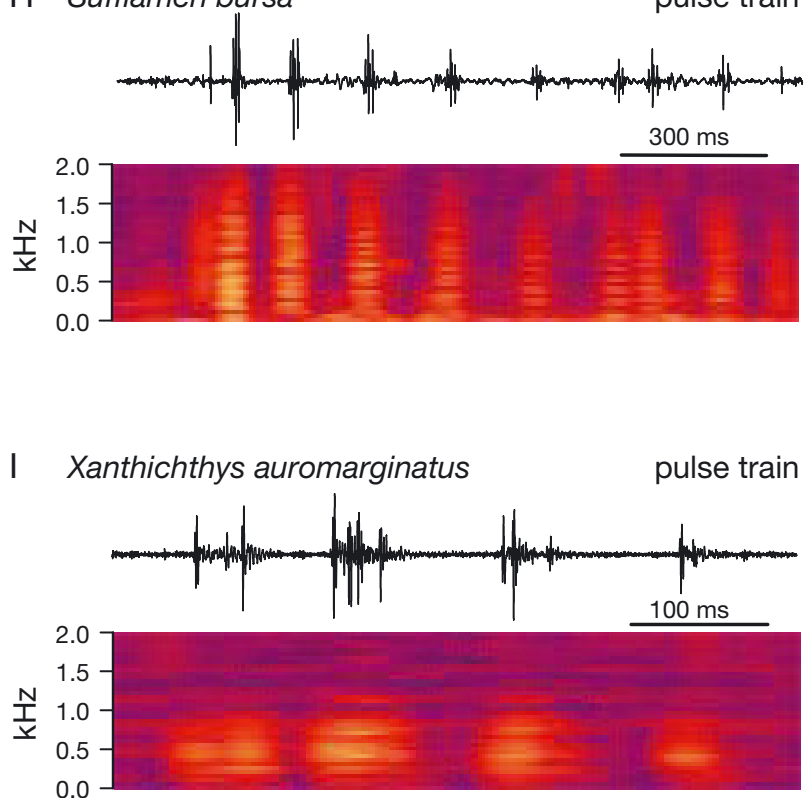

Fig. 2. Waveforms and spectrograms of agonistic sounds produced by fish at Puako reef, Hawai'i, HI, USA. Scientific names are given in the figure. (A) Peacock grouper pulse sounds during social interactions with conspecifics, (B) multiband butterflyfish pulse sound during agonistic bouts with a conspecific, (C) high-frequency pulse sound by the Indo-Pacific sergeant during nest defense, $(\mathrm{D}, \mathrm{E})$ pulse train and growl 2 sounds by the blue-eye damselfish during defense of coral territory, $(F)$ half pulse sound by the Hawaiian gregory during defense of feeding territory, (G) rasp sound produced by the black durgon triggerfish during social interactions, $(\mathrm{H})$ pulse train sound by the lei triggerfish during social interactions, and (I) pulse train sound of gilded triggerfish social interactions. Relative intensity of sounds across the frequency spectrum is indicated from low (dark purple) to high (bright yellow) in spectrograms 
pulse (Agg12) identified by 1 to 2 pulses per sound and longer pulse trains (Agg $>2$ ) identified by $>2$ pulses as reported by Maruska et al. (2007). A new agonistic high-frequency pulse sound (Fig. 2C) was of much shorter duration (18-23 ms) and higher peak frequency $(805-1162 \mathrm{~Hz})$ but was not produced in pulse trains.

The most prolific production of agonistic sounds was observed in the territorial blue-eye damselfish Plectroglyphidodon johnstonianus. These coral-feeders produced single pulse and train sounds directed towards neighboring conspecifics and when experimentally evoked by introduction of a bottled coralfeeding multiband butterflyfish C. multicinctus near their territory (Table S2). The single pulse sound was of short duration (33 ms) with a peak frequency of $284 \mathrm{~Hz}$ and is similar in characteristics with the pulses produced in a pulse train (Fig. 2D). We also recorded 2 growl sound types, which occurred as a series of contiguous pulses of much longer event duration (125-403 ms) and higher peak frequency $(125-403 \mathrm{~Hz})$ than the half pulse sound. The growl 1 sound had a rapid regular pulse-emission rate and pulse amplitude, whereas the growl 2 sound (Fig. 2E) had more variable pulse emission rates and pulse amplitudes. A half pulse sound waveform was identified by a distinctive single, strong, and rapid negative peak followed by a slower positive half cycle. Half pulses were of similar short duration $(40 \mathrm{~ms})$ to single pulses but were lower in peak frequency $(49 \mathrm{~Hz} ; \mathrm{p}=0.024, t$-test $t=-3.0, \mathrm{df}=6)$. Very similar pulse and half pulse sounds (Fig. 2F) were recorded for the Hawaiian gregory Stegastes marginatus that defends algal turf feeding and breeding territories (Table S2). Pulse train sounds were recorded for threespot chromis Chromis verater during agonistic interactions with a conspecific and the 'aggressive' sound (Mann \& Lobel 1998) produced during agonistic chases by the Hawaiian dascyllus Dascyllus albisella (Table S2).

Wrasses and parrotfishes (Labridae). Pulsed sounds and trains were recorded during agonistic chases with conspecifics for the male bird wrasse Gomphosus varius and the male bullethead parrotfish Chlorurus spilurus (Table S2) and are described below in the section on reproductive behaviors.

Surgeonfishes (Acanthuridae) and Moorish idol (Zanclidae). The Moorish idol Zanclus cornutus produced sounds during aggressive interactions and during apparent courtship behaviors (Table S2). These included both single pulsed sounds and trains that ranged from 30 to $102 \mathrm{~ms}$ in duration and peak frequencies from 176 to $520 \mathrm{~Hz}$. Brief pulsed sounds of average peak frequency from 200 to $556 \mathrm{~Hz}$ were recorded during agonistic (and courtship) behaviors primarily directed toward conspecifics for the orangeband surgeonfish Acanthurus olivaceus, the Hawaiian bristletooth Ctenochaetus hawaiiensis, the goldring bristletooth surgeonfish $C$. strigosus, and the yellow tang Zebrasoma flavescens (Table S2). A long pulse sound that was of longer duration $(120 \mathrm{~ms})$ than the single pulse $(30 \mathrm{~ms})$ was recorded for a single $C$. hawaiiensis.

Triggerfishes (Balistidae). Agonistic acoustic behaviors during social interactions were recorded for 3 triggerfishes (Table S2). The loud thump-like pulse sound produced during agonistic chases among black triggerfish Melichthys niger was of relatively short duration (68 ms) and low peak frequency ( $86 \mathrm{~Hz})$. In contrast, the rasp-like pulse sound was of longer duration $(319 \mathrm{~ms})$ and higher peak frequency $(313 \mathrm{~Hz}$; Fig. 2G). The lei triggerfish Sufflamen bursa readily produced pulsed sounds when engaged in agonistic chases, territory defense, and nest-guarding behaviors (by females) and occurred as single pulses or pulse trains $\left(9.8+2.8 \mathrm{SE}\right.$ pulses train $^{-1}$; Fig. $\left.2 \mathrm{H}\right)$ with a peak frequency of $583 \mathrm{~Hz}$. The planktivorous and territorial gilded triggerfish Xanthichthys auromarginatus produced pulses of relatively short duration (58 $\mathrm{ms}$ ) and $287 \mathrm{~Hz}$ peak frequency primarily in trains during chases with conspecifics (Fig. 2I).

\section{Reproductive behaviors - courtship and spawning}

A total of 32 reproduction-related sounds were recorded for a total of 18 species across the butterflyfish, damselfish, parrotfish, and surgeonfish families, as well as wrasses and Moorish idol. The majority were associated with courtship behaviors and spawning (Fig. 1).

Butterflyfishes. The planktivorous pyramid butterflyfish $H$. polylepis was not acoustically active during daytime feeding in the water column. However, late in the afternoon on some days, males established courtship territories on the bottom ( $>15 \mathrm{~m}$ deep) that they defended from other males and that were visited by pre-spawn females (identified by their swollen abdomen filled with hydrated eggs). During these interactions, males produced loud single and train pulse sounds as recently reported (Boyle \& Tricas 2011). Further analyses showed that these sounds (peak frequency $=144-147 \mathrm{~Hz}$ ) are produced as either discrete pulses (84 ms duration) or blended pulses that have no interpulse separation (186 ms duration; Table S2). We recorded a pulse sound dur- 

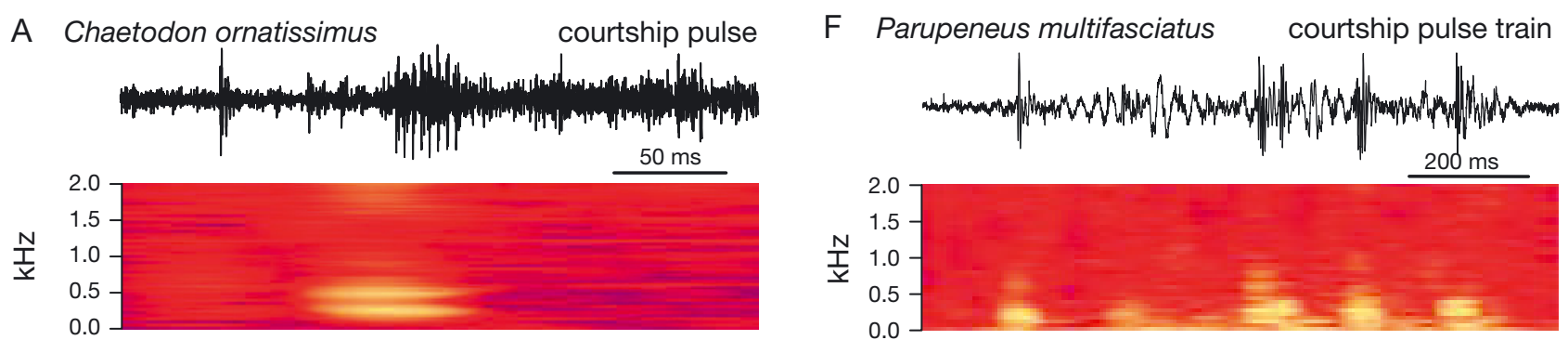

B Thalassoma duperrey

spawning pulse I

\section{G Parupeneus multifasciatus}

courtship hf pulse
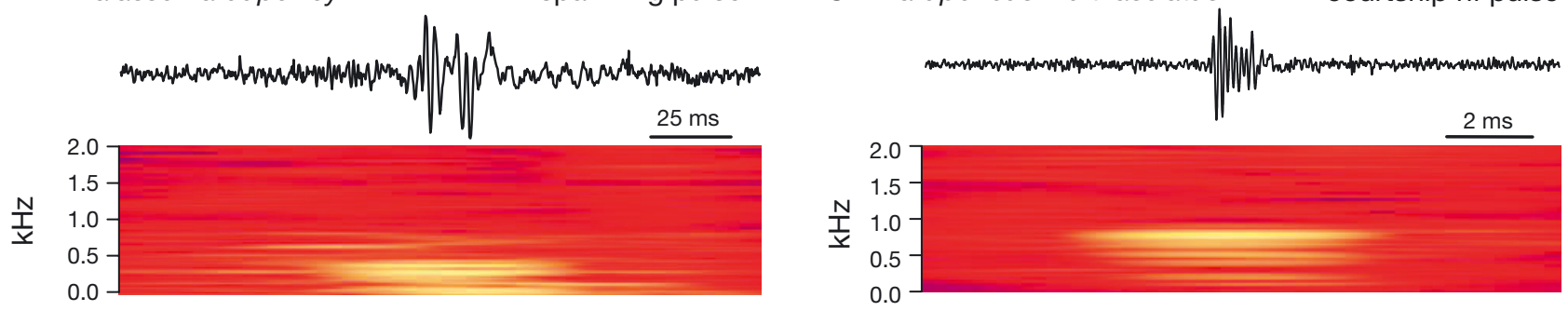

C Gomphosus varius spawning pulse I train

H Acanthurus olivaceus courtship pulse
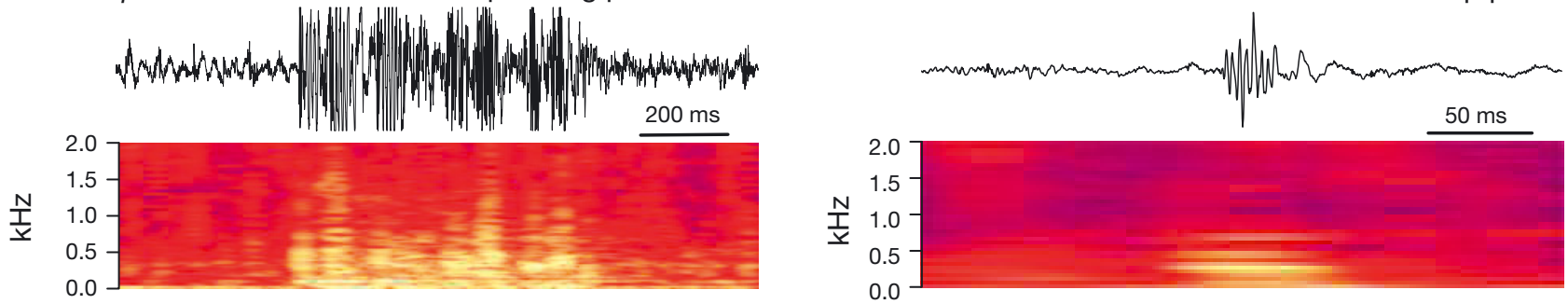

D Gomphosus varius

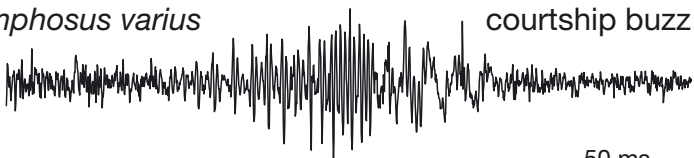

I Zebrasoma flavescens

spawning pulse
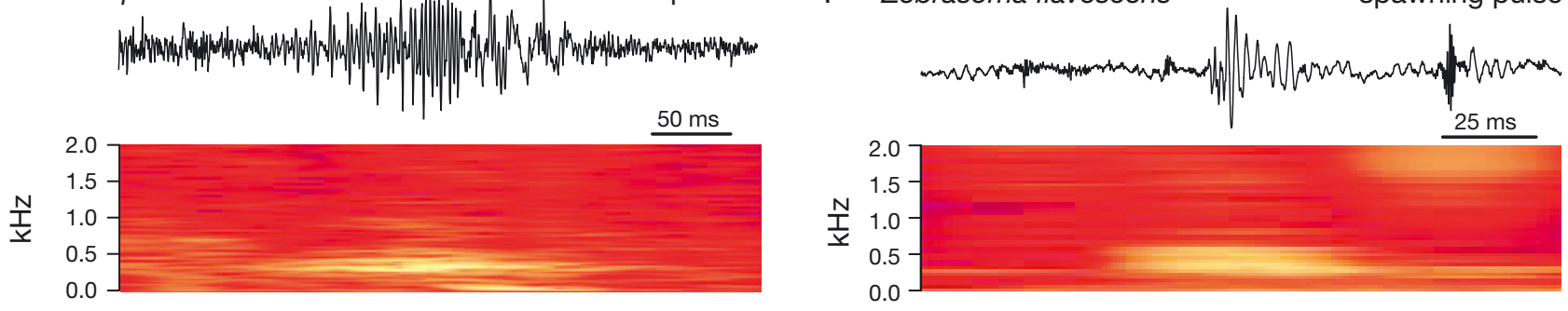

E Chlorurus spilurus courtship low frequency train

J

J Zebrasoma flavescens

courtship pulse
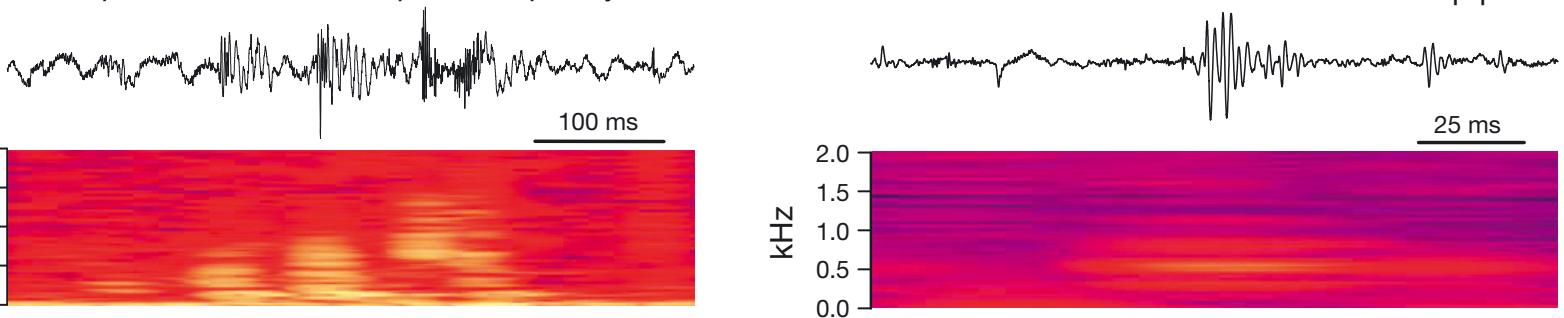

Fig. 3. Waveforms and spectrograms of reproductive sounds produced by fish at Puako reef, Hawai'i, HI, USA. Scientific names are given in the figure. (A) Courtship pulses by the ornate butterflyfish, (B) pulse I sound during spawning by the saddle wrasse, (C) spawning pulse I train during spawning by the bird wrasse, (D) courtship buzz sound by a male bird wrasse, (E) low-frequency pulse train by the bullethead parrotfish during courtship with females, $(F, G)$ pulse train (peak frequency $\sim 140 \mathrm{~Hz}$ ) and brief high-frequency (hf) pulse (peak frequency $\sim 830 \mathrm{~Hz}$ ) by male manybar goatfish during courtship, (H) short pulse by olive surgeonfish during courtship, (I) pulse sound produced by yellow tang during a spawning rush, (J) pulse sound produced during courtship by a pair of yellow tangs. Relative intensity of sounds across the frequency spectrum is indicated from low (dark purple) to high (bright yellow) in spectrograms 
ing courtship by a pair of ornate butterflyfish $C$. ornatissimus (Fig. 3A) which was similar to their agonistic sound (described above).

Damselfishes. Three previously reported sounds (Lobel \& Mann 1995, Mann \& Lobel 1998) were recorded for the Hawaiian dascyllus $D$. albisella. The 'signal jump' was produced by courting males and the mate/visit sound during visits and spawning by females at the coral nest site. The aggressive pulse was indistinguishable from the signal jump, so these 2 sounds were pooled in our analysis (Table S2).

Wrasses and parrotfishes. Several single pulse and train event sounds were recorded during reproductive behaviors of the bird wrasse $G$. varius and the saddle wrasse Thalassoma duperrey (Table S2). Single pulse I sounds (Fig. 3B) were produced by both species during courtship and spawning behaviors and discriminated by their relatively long duration (57-85 ms) compared to the shorter pulse II sound (11-28 ms) that was recorded only during courtship (per Boyle \& Cox 2009). Both pulse types were also produced in trains (Fig. 3C) that were of similar peak frequency and pulse duration as single pulses (Table S2). One courting G. varius male produced a unique buzz sound that lasted for $141 \mathrm{~ms}$ and had a peak frequency of $371 \mathrm{~Hz}$ (Fig. 3D), but this acoustic behavior was very rare. Our recordings of male $T$. duperrey in courtship also identified a new blended pulse I sound that lacked clear interpulse intervals.

Large terminal-phase male bullethead parrotfish C. spilurus establish feeding territories with female harems along the reef slope at $\geq 20 \mathrm{~m}$ depth. Males produced distinct sounds associated with both aggressive chases of other males and during reproductive behaviors with females (Table S2). Loud, single low-frequency pulses were of relatively long duration (252 $\mathrm{ms}$ ) compared to those produced in trains (45 ms; Fig. 3E) but were of similar peak frequency (111 vs. $137 \mathrm{~Hz}$, respectively). Similar sounds were recorded during spawning events high in the water column, but we were unable to analyze spawning sounds due to poor signal to noise ratios.

Goatfishes. Recurrent sounds associated with reproductive activities were identified for the island goatfish Parupeneus insularis and manybar goatfish P. multifasciatus (Table S2) primarily near peak and outgoing tides. Males of both species produced lowfrequency single pulse and train sounds during courtship chases of females (Fig. 3F). Single and train sound events within these 2 species were similar in duration $(\mathrm{p}=0.38$, Mann-Whitney $U$-test, $U=5.0, \mathrm{n}=$ 3 and 6 , respectively, for $P$. insularis; $\mathrm{p}=0.62$, $t$-test, $t=-0.53$, df $=6$ for $P$. multifasciatus) and peak fre- quency ( $\mathrm{p}=0.71$, Mann-Whitney $U=7.0, \mathrm{n}=3$ and 6 , respectively, for $P$. insularis; $\mathrm{p}=0.88, t=0.156, \mathrm{df}=6$ for P. multifasciatus). Male P. multifasciatus also produced a courtship high-frequency single pulse sound (Fig. 3G) which was of very short average duration $(18 \mathrm{~ms})$ and of higher peak frequency $(833 \mathrm{~Hz})$ than the other pulsed sounds $(139 \mathrm{~Hz})$ recorded for this species $(\mathrm{p}<0.001, t=8.80, \mathrm{df}=8)$.

Surgeonfishes and Moorish idol. Similar but infrequent courtship and agonistic sounds were recorded from the Moorish idol Z. cornutus and several acanthurids (described above, Table S2): the orangeband surgeonfish A. olivaceus (Fig. 3H), the Hawaiian bristletooth $C$. hawaiiensis, the goldring bristletooth C. strigosus, and the yellow tang $Z$. flavescens (Table S2). In contrast, high numbers of sounds were recorded during the pronounced reproductive activity of $Z$. flavescens at the Puako study site where hundreds or thousands of fish formed widespread aggregations above the deep reef slope (Table S2). Individual females with hydrated eggs were approached and courted by males, and then spawned in a rapid upward spawning rush often with several males. We identified short pulse sounds associated with spawning (Fig. 3I) and courtship (Fig. 3J) behaviors which were of similar duration (40-42 ms) and peak frequency (274-349 Hz; Table S2), but we were not able to confirm whether sounds were made by males, females, or both sexes. We also observed a longer and more variable 'collision' pulse sound that occurred during fast movements of fish in small groups as they engaged in agonistic and spawning interactions (Table S2), and assume that this sound was caused by the physical impact of the bodies of individual fish. Large populations of the lavender tang A. nigrofuscus formed similar spawning assemblages during the study, but no reproductive sounds were identified for this species.

\section{Feeding behaviors}

Parrotfishes. Broadband sounds that resulted from the scraping of teeth on hard benthic substrate during feeding were recorded for adult bullethead parrotfish C. spilurus, palenose parrotfish Scarus psittacus, and ember parrotfish S. rubroviolaceus (Table S2, Fig. 4A-C). Average duration of feeding sound scrapes for these species ranged from 87 to $181 \mathrm{~ms}$, and were of relatively high peak frequency (1277$3387 \mathrm{~Hz}$ ) and broad bandwidth. Note that a single bite usually produced interrupted sound waveforms presumably caused by motion of the teeth over small 
Fig. 4. Waveforms and spectrograms of feeding sounds produced by the bite action of oral jaws and teeth upon hard food substrates by benthic feeding fish on Hawaiian coral reefs. Scientific names are given in the figure. (A) Feeding bite sound by the bullethead parrotfish, (B) feeding bite sound by the redlip parrotfish, $(\mathrm{C})$ feeding bite sound by the palenose parrotfish. Note high peak frequency and bandwidths produced as parrotfish scrape algae and diatoms from dead coral rock. (D) Feeding bite sound by the black durgon triggerfish that feeds on benthic invertebrates, (E) feeding bite sound by the barred filefish that feeds on live hard coral. Relative intensity of sounds across the frequency spectrum is indicated from low (dark purple) to high (bright yellow) in spectrograms.

Start of bite waveforms is indicated by arrows

irregularities in the substrate. These feeding sounds showed the highest frequency spectrum (max. bandwidth quartile range $=6157-8860 \mathrm{~Hz}$, Table S2) of all sounds recorded in this study.

Triggerfishes and filefishes. Sounds were produced during benthic feeding by filefish and triggerfish. The black triggerfish $M$. niger produced a scrape sound when feeding on hard benthic substrates (Fig. 4D) that was of relative short duration (63 ms) but of high peak frequency $(3973 \mathrm{~Hz}$ ) similar to parrotfish feeding. The barred filefish Cantherines dumerilii also produced an audible scrape sound (Fig. 4E) when feeding on live coral Pocillopora spp. but was of very low peak frequency $(35 \mathrm{~Hz})$.

\section{Schooling}

We recorded pulse sounds produced by species in schools or aggregations near the reef. The bicolor anthias Pseudanthias bicolor and bluestripe snapper Lutjanus kasmira formed schools at depths > 20 m that produced infrequent short pulse sounds (Table S2). Single pulse and train sounds were produced by white saddle goatfish Parupeneus porphyreus that foraged in groups of $<5$ individuals and larger non-feeding schools over the reef. Large schools of yellowfin goatfish Mulloidichthys vanicolensis and the yellowstripe goatfish $M$. flavolineatus were frequently encountered on the reef, but only 1 poorquality pulse sound was recorded for the latter species.

\section{Vigilance behavior — responses to divers or predators}

Several species produced sounds in response to the approach of a diver or a potential fish predator. In these cases, we categorized the diver's presence as a disturbance stimulus and the response of the fish as vigilance (alert) behavior.

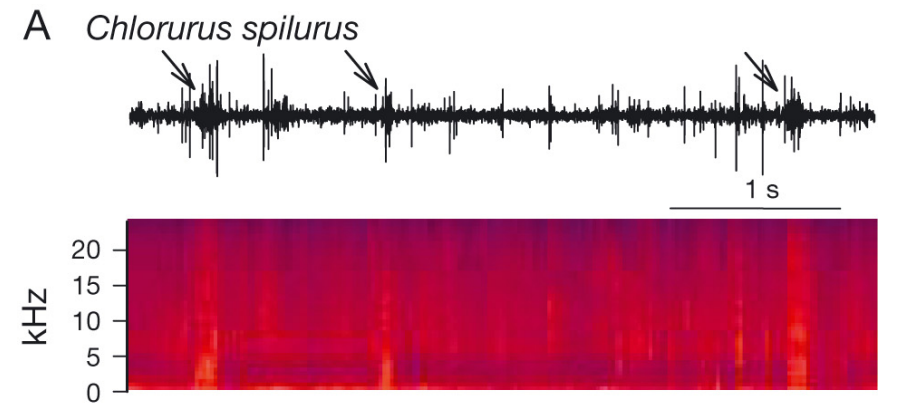

B Scarus rubroviolaceus
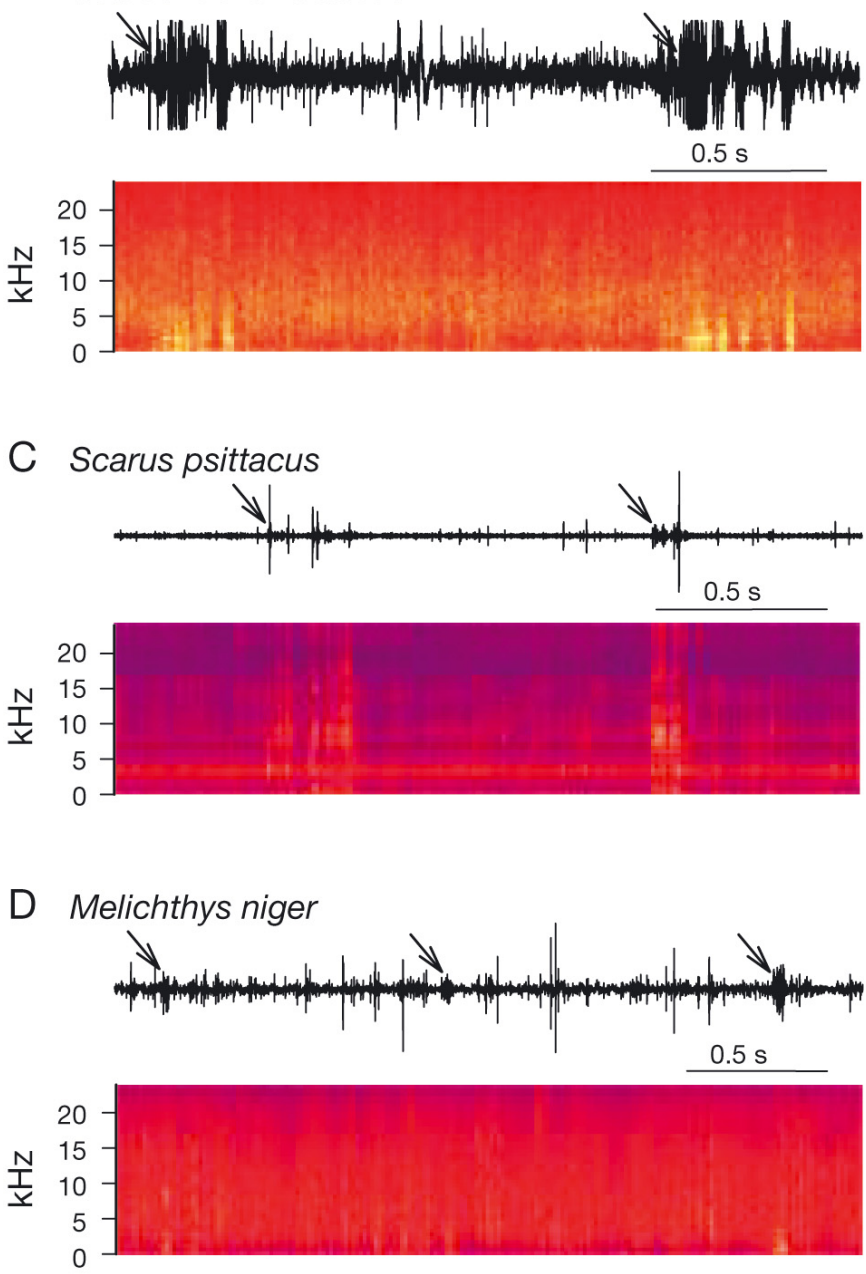

E Cantherhines dumerilii

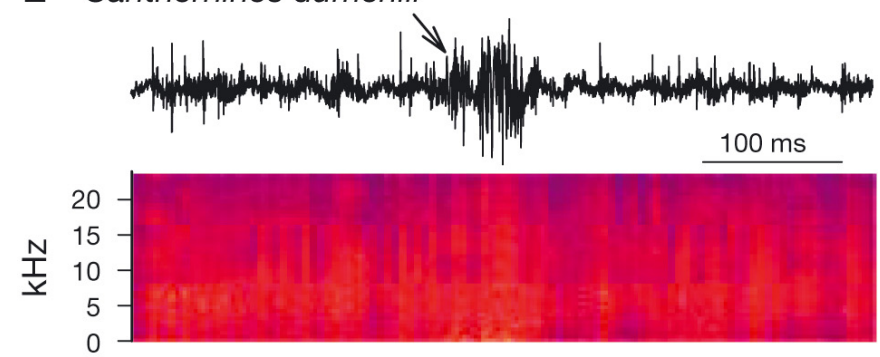


Squirrelfishes and soldierfishes. Numerous holocentrid species were observed on the open reef or within/near reef crevices during daylight hours and produced a wide range of vigilance sounds (Table S2), many of which were reported previously (e.g. Winn et al. 1964, Salmon 1967, Horch \& Salmon 1973). Large groups of $\sim 3$ to 20 epaulette soldierfish Myripristis kuntee formed stationary and relatively inactive aggregations over the coral reef bottom and produced sounds when approached by divers or large predatory fish (e.g. carangids). Knock pulses (Fig. 5A) were usually first produced by the fish nearest to the diver (identified by the coincident erection of the dorsal fin or turning behavior) followed by more knock sounds from other individuals as they moved towards shelter. The grunt (Fig. 5B) and staccato sounds were produced more intermittently. Similar acoustic vigilance responses were observed for the soldierfish $M$. berndti and $M$. amaena, which inhabit caves or reef shelters during the day. The more solitary Sammara Neoniphon sammara and goldlined N. aurolineatus squirrelfish produced loud pulsed growls, grunts, knocks or staccato sounds. Growl sounds consisted of a rapid series of contiguous pulses that decreased in rate over time. On several occasions, additional sounds were recorded after alert and vocalizing $N$. sammara or Myripristis entered the reef with other holocentrids, but the source of those sounds could not be confirmed.

We recorded several new vigilance sounds from blue-lined squirrelfish Sargocentron tiere found under exposed ledges or within small spaces of the reef (Table S2, Fig. 5C-E). The growl sound was of relatively long duration (395 ms) and had a mean peak frequency of $202 \mathrm{~Hz}$. The grunt occurred as a single pulse with a shorter mean duration (74 ms) but similar peak frequency $(191 \mathrm{~Hz})$. The knock sound was produced as a train of pulses with a peak frequency of $387 \mathrm{~Hz}$. We also observed sounds from the larger congener, the saber squirrelfish $S$. spiniferum, but poor recording quality precluded analysis.

All growl, grunt, knock, and staccato sounds were recorded from $M$. berndti, but all remaining holocentrids produced at least 3 sound types (Table S2). The growl was produced by at least 1 species of all 4 genera and consisted of 1 to 9 events with a relatively long duration (80-591 ms). Although there are indications of possible pulse duration and frequency differences among sound types (e.g. knock: 7-28 ms, $387-926 \mathrm{~Hz}$ vs. other sound types), our low sample sizes precluded statistical comparisons among sounds and species.

Angelfishes and butterflyfishes. Vigilance sounds were recorded for 2 of 3 angelfish species (Table S2).
A Myripristis kuntee

knock
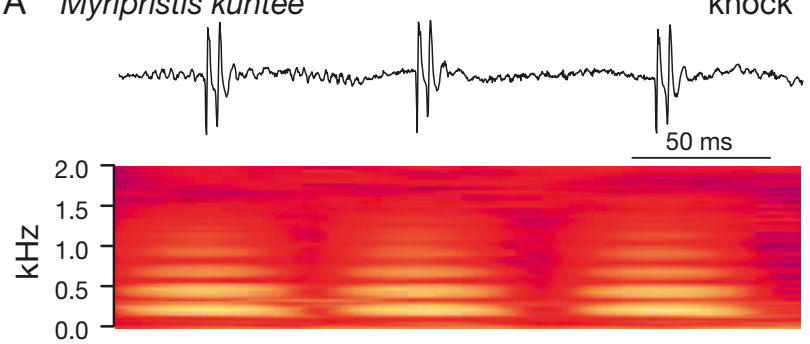

B Myripristis kuntee

grunt
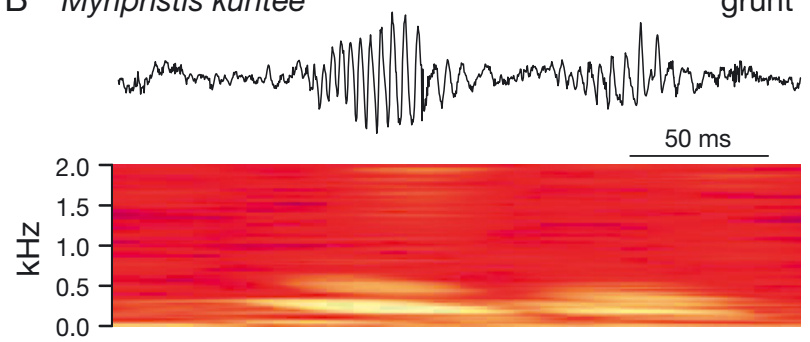

C Sargocentron tiere

growl
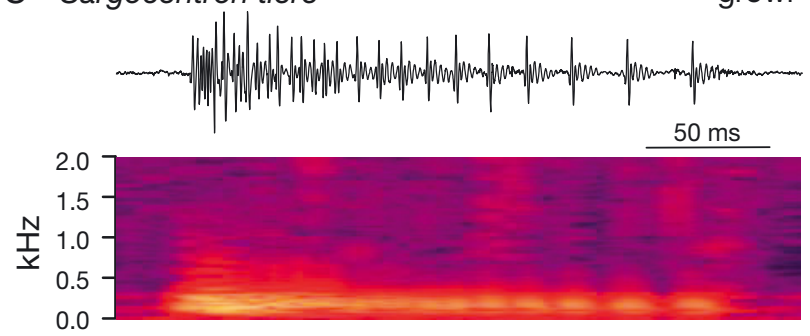

D Sargocentron tiere

grunt

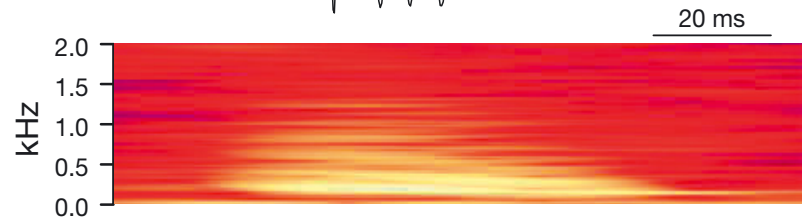

E Sargocentron tiere

knock
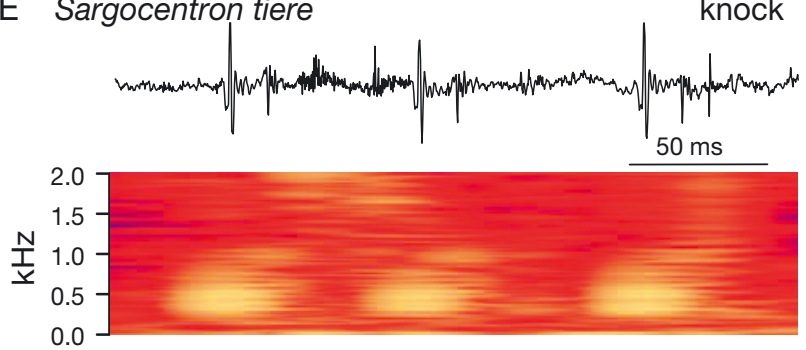

Fig. 5. Waveforms and spectrograms of sounds associated with vigilance that are produced by fish on Hawaiian coral reefs after approach by divers or predators. Scientific names are given in the figure. $(\mathrm{A}, \mathrm{B})$ Grunt and knock sounds by epaulette soldierfish that rest unsheltered near the coral substrate during daylight hours; (C-E) growl, grunt, and knock sounds by bluelined squirrelfish within shelter of the reef. Relative intensity of sounds across the frequency spectrum is indicated from low (dark purple) to high (bright yellow) in spectrograms 
The flame angel Centropyge loriculus and bandit angelfish Apolemichthys arcuatus produced similar short pulse sounds when approached by divers, but these were rare. Short pulse sounds were produced by the multiband butterflyfish C. multicinctus (indistinguishable from the agonistic sound), the pyramid butterflyfish $H$. polylepis (similar to the courtship sound), and Thompson's butterflyfish $H$. thompsoni. Overall, there was a narrow peak frequency range for single pulse, pulse train, and blended pulse sounds (144$170 \mathrm{~Hz}$ ) produced by both species of Hemitaurichthys. A pulse disturbance sound was recorded from the forcepsfish Forcipiger flavissimus, which showed the highest recorded peak frequency $(840 \mathrm{~Hz})$ of any butterflyfish vigilance sound.

Damselfishes. Three species of planktivorous damselfish produced pulsed sounds when approached by divers near the reef substrate (Table S2). Single pulses of similar duration (154-186 ms) and low peak frequency $(27-35 \mathrm{~Hz})$ were recorded for the oval chromis C. ovalis, and threespot chromis C. verater. A high frequency vigilance pulse produced by the chocolate-dip chromis C. hanui was also of short duration $(22 \mathrm{~ms})$ but higher peak frequency $(1012 \mathrm{~Hz})$.

Triggerfishes. Pulse train sounds were recorded for the lei triggerfish $S$. bursa (previously described in agonistic behaviors) and a single pulse sound for the gilded triggerfish $X$. auromarginatus when some fish were approached by divers.

\section{General characteristics of reef fish sounds}

Single event sounds were recorded for at least 1 species in 12 fish families and were of short duration (range $=7-385 \mathrm{~ms}$, median $=59 \mathrm{~ms}, \mathrm{n}=39$ ). In comparison, the mean number of events in trains ranged from 1.15 to 10.5 among species, and their duration (median $=52 \mathrm{~ms}, \mathrm{n}=45$ ) did not differ from single pulse events (total range $=7-591 \mathrm{~ms}, \mathrm{p}=0.94$, MannWhitney $U=868$ ). The 85 sound types covered a broad spectrum of peak frequencies from 27 to $3609 \mathrm{~Hz}$ with a mean of $475 \pm 75 \mathrm{SE} \mathrm{Hz}$ (Table S2, Fig. 6). However, peak frequencies were not normally distributed (Kolmogorov-Smirnov test, $\mathrm{p}<0.001$ ) and were biased towards a low-frequency range with a mode of 100 to $300 \mathrm{~Hz}$ and median of $285 \mathrm{~Hz}$.
A bivariate plot of pulse duration and peak frequency for non-feeding sounds shows a non-linear and inverse relationship with great overlap among fish families (Fig. 7). Sounds with peak frequency $>500 \mathrm{~Hz}$ were generally of short duration $(<50 \mathrm{~ms})$ and were produced by several damselfishes, squirrelfishes, butterflyfishes, and goatfishes, with the exception of 2 labrid sounds of longer duration (L symbols in Fig. 7). In comparison, several low-frequency sounds could be distinguished by their relatively long pulse duration (>100 ms); these were made by several species that include squirrelfish, damselfish, surgeonfish, and triggerfish.

There was great overlap in sound frequency spectra among species and behavioral contexts (Fig. 8). Lowfrequency sounds $<100 \mathrm{~Hz}$ were recorded for several unrelated species that include Sargocentron spiniferum soldierfish (alert call), bluestripe snapper $L$. kasmira (shoaling), peacock grouper C. argus (aggression), Hawaiian bristletooth acanthurid Ctenochaetus hawaiiensis (courtship aggression), and the barred filefish C. dumerilii (feeding on live coral). The feeding sounds of parrotfishes were of higher peak frequency than social sounds of all reef fishes (range $=$ $<47-8156$ vs. $18-3609 \mathrm{~Hz}$, median $=2953$ vs. $245 \mathrm{~Hz}$, $\mathrm{n}=29$ and 164, $\mathrm{p}<0.001$, Mann-Whitney $U=928$ ). Parrotfish feeding sounds occupied a wider portion of the $0-24 \mathrm{kHz}$ frequency band than did social sounds of reef fishes as shown in Fig. 8: $-6 \mathrm{~dB}$ bandwidth (range $=0.46-7.42$ vs. $0.05-7.62 \%$, median $=3.0$ vs. $1.0 \%, \mathrm{n}=29$ and 164, $\mathrm{p}<0.001$, Mann-Whitney $U=$ 518) and Table S2: $-10 \mathrm{~dB}$ bandwidth (range $=$ $1.57-16.67$ vs. $0.11-12.31 \%$, median $=7.0$ vs. $1.0 \%, \mathrm{n}$ $=29$ and 164, $\mathrm{p}<0.001$, Mann-Whitney $U=141$ ). 


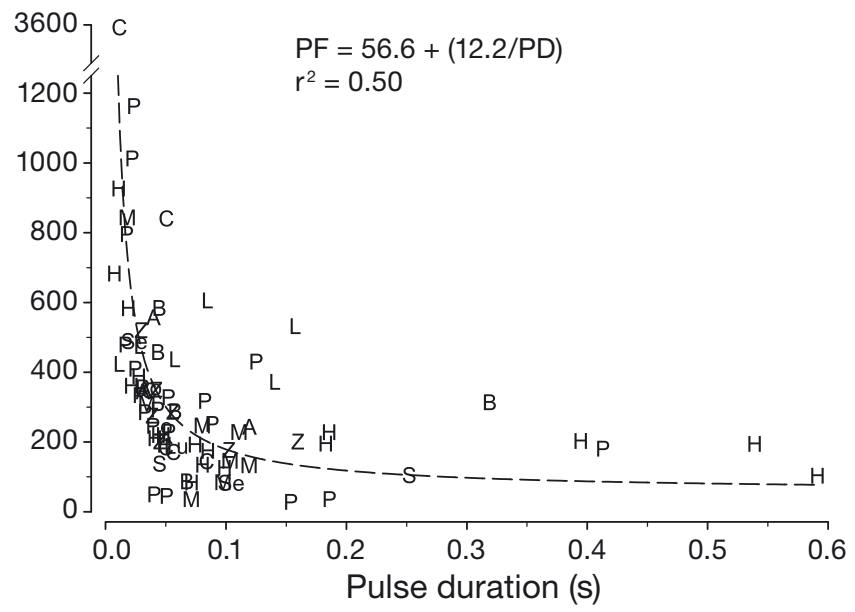

Fig. 7. Relationship between event duration and peak frequency of sounds produced by species in 13 families of coral reef fishes. Data are shown for single pulse events, not pulse trains. Sounds associated with feeding scrapes by scarines, monacantids, and balistids are not included. Curve fit to inverse polynomial model for peak frequency $(\mathrm{PF})$ as a function of pulse duration (PD). A = Acanthuridae, $\mathrm{B}=$ Balistidae, $\mathrm{Ch}=$ Chaetodontidae, $\mathrm{H}=$ Holocentridae, $\mathrm{L}=$ julidine labrids, $\mathrm{Lu}=$ Lutjanidae, $\mathrm{M}=$ Mullidae, $\mathrm{Mo}=$ Monacanthidae, $\mathrm{P}=$ Pomacentridae, $\mathrm{Po}=$ Pomacanthidae, $\mathrm{Se}=$ Serrandiae, $\mathrm{S}=$ scarine labrids, Z = Zanclidae

\section{DISCUSSION}

The 45 sonic species identified in this study present the most comprehensive acoustic survey for a coral reef fish community to date. Previous multi-species studies used remote stationary hydrophone and video systems (Cummings et al. 1964, 1966, Kumpf 1964) but had limited ability for identification of the acoustic species. A rebreather survey in the Tektite habitat program recorded several sounds for at least 10 species (Bright 1972) but was limited to a duration of a few weeks. These and other previous studies have produced quantitative acoustic data for about 100 species (summarized by Lobel et al. 2010, their Table 10.1). It is significant that we focused on species that were conspicuous and engaged in overt behaviors and did not target small, sedentary, or cryptic species (e.g. gobies and blennies) which are soniferous on other reefs. Furthermore, our study was limited to daylight hours in spring and summer months so we did not survey many nocturnal species or other seasons. Thus our sound library for a Hawaiian reef fish community presents an underestimate of the number of acoustic species but nonetheless represents an approximate $50 \%$ increase in the total number of acoustic coral reef species for which quantitative data are now available.

\section{Behavioral contexts of reef fish sounds}

Agonistic behaviors

Many sounds were produced by fish engaged in non-reproductive agonistic contexts that include aggressive interactions between 2 or more individuals such as threat displays, attacks, chases, and retreats (Fig. 1) as occur widely among other freshwater and marine species (reviewed by Ladich 1997). Sound production during non-reproductive agonistic interactions occurred among pairs of conspecific acanthurids (Ctenochaetus sp., Zebrasoma flavescens) and within haremic social groups (Cephalopholis argus and Forcipiger flavissimus). The most prolific agonistic behaviors occurred during defense of food and nesting sites by the herbivorous Hawaiian gregory (e.g. Stegastes marginatus) and coral feeding blueeye damselfish (e.g. Plectroglyphidodon johnstonianus). Other species also produced sound during defense of solitary (e.g. lei triggerfish Sufflamen bursa and possibly the gilded triggerfish Xanthichthys auromarginatus) and colonial sergeant (Abudefduf abdominalis and $A$. vaigiensis) nests.

\section{Courtship and spawning}

Reproductive sounds are well known for damselfishes (Lobel et al. 2010), but we recorded courtship sounds only for the Hawaiian dascyllus Dascyllus albisella. The lack of damselfish reproductive sounds in this study is likely due to inconspicuous nesting sites, non-coincident spawning seasons, and our limited observation time for each species. Courtship or spawning sounds occurred during peak and outgoing tides for island Parupeneus insularis and manybar $P$. multifasciatus goatfishes, ornate Chaeotodon ornatissimus and pyramid Hemitaurichthys polylepis butterflyfishes, and saddle Thalassoma duperrey and bird Gomphosus varius wrasses. Male bullethead parrotfish Chlorurus spilurus produced pulse courtship sounds, but we were unable to record pulsed or hydrodynamic sounds associated with the upward spawning rush as reported for the striped parrotfish Scarus iseri (Lobel 1992). Brief courtship pulse sounds were produced by several surgeonfishes (Acanthurus olivaceus, Ctenochaetus hawaiiensis, and C. strigosus) and the Moorish idol Zanclus cornutus which frequently interact as pairs prior to spawning. Most remarkable were the several forms of courtship and spawning pulses produced in large spawning aggregations of yellow tang Zebrasoma flavescens. These 


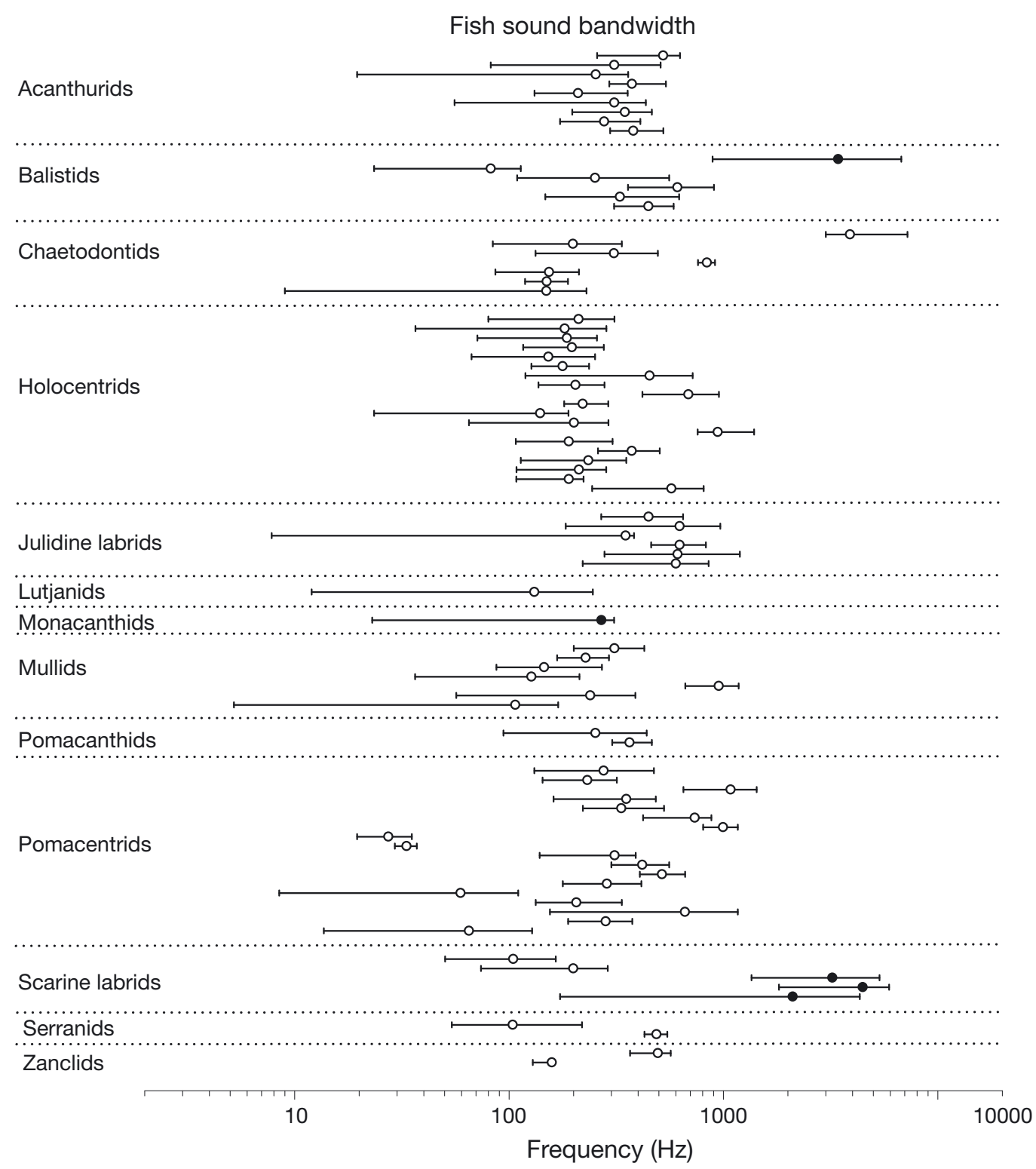

Fig. 8. The $6 \mathrm{~dB}$ bandwidth of non-feeding and feeding sound types recorded for 45 species of fishes on Hawaiian coral reefs. Median peak frequency is indicated for non-feeding (open circles) and feeding (solid circles) sounds. Note high peak frequency and bandwidths for feeding sounds of parrotfishes (scarines) and 1 balistid

results reveal a diversity of sounds associated with courtship behaviors for several reef species. Future studies should focus on recording species-specific acoustic behaviors associated with the spawning act.

Vigilance, alarm, or alert calls

The production of sound after physical disturbance, handling, or electric shock is often used to identify sonic species in the lab (Fish \& Mowbray 1970). Many species in our study produced sounds in response to the close approach by a diver which we conservatively categorized as vigilance or alert sounds. Most notable were the squirrelfish and soldierfishes, which are highly vocal and known to make many of these calls in the presence of predators (Salmon 1967), and many are produced during agonistic and social communication. The production of pulsed sounds in response to divers was observed for several damselfish, triggerfish, and filefishes and likely functions in an agonistic context, as with many other members of these families. Further experiments are necessary to place the new calls 
produced in response to divers into a biologically relevant context for each species.

\section{Feeding sounds}

The production of adventitious sounds during feeding is best described for parrotfishes (Lobel et al. 2010, their Table S2). We recorded similar incidental feeding sounds for 3 species of parrotfish during their normal foraging on dead coral substrates. These sounds were distinctive primarily by their long bite duration (87-181 ms) and high peak frequency spectrum $(1277-3387 \mathrm{~Hz})$. Acoustic analyses of feeding sounds of several Caribbean parrotfishes showed the production of high-frequency scrape and crunch sounds that can be used to distinguish feeding activities of small and large individuals (but not species) based on sound duration, frequency spectra, and the temporal spacing of sound waves within a bite sound (Sartori \& Bright 1973). The occurrence of these distinctive sounds is a good indicator of the feeding activity by this important family of herbivorous fishes and may be used as a potential measure of reef bioerosion. Our few observations of the coincident production of feeding sounds by the corallivorous barred filefish Cantherines dumerilii and the hard-benthos feeder black durgon Melichthys niger are consistent with feeding sounds reported for other triggerfishes and filefishes (Moulton 1958, Steinberg et al. 1965, Fish \& Mowbray 1970). Sounds from these and other benthic feeding hard-tooth species may also be of potential use in estimates of their feeding activity in coral reef environments and rates of fish-induced bioerosion.

\section{Reef noise and fish sound spectra}

The peak frequency of most pulse sounds in our study ranged from 100 to $300 \mathrm{~Hz}$ and was near or within the low-frequency band of ambient noise that is generated by wind, tidal flow, and anthropogenic activities (Wenz 1962, Myrberg 1980, Urick 1983). Several fish sounds showed peak frequencies $<100 \mathrm{~Hz}$, the band which can be dominated by wind-generated noise at the surface. Thus high signal-to-noise fish sounds in this low-frequency band are best recorded in calm wind and wave conditions as occurs on leeward rather than the windward reefs that are subject to relatively strong and continuous trade winds.

The higher frequency band of $100-2000 \mathrm{~Hz}$ is dominated by fish sounds on other coral reefs (Cato 1980) and includes the peak frequencies and bandwidth of most of our fish sounds. Although most sounds in this study had peak energy at the low end of this range, the -6 and $-10 \mathrm{~dB}$ bandwidths span a much broader spectrum and are similar to that reported for fish vocalizations on a north Australian reef (Cato 1980). Many of those sounds were uninterrupted tones of several seconds in duration, showed strong harmonics, and occurred primarily during nocturnal hours. Of note was the diurnal sound type ' $\mathrm{C}$,' which was described as a steady rhythmic pulsing knock sound. These low-frequency energy peaks observed in our study are generally below the $400 \mathrm{~Hz}$ to $4 \mathrm{KHz}$ band of evening acoustic choruses of biological origin reported for coral reefs in the Timor Sea and west Pacific Ocean (Cato 1978). Recent work on the soundscapes of a Pacific reef in Panama shows a strong diurnal peak near $400 \mathrm{~Hz}$ that was attributed to acoustic activity of Stegastes acapulcoensis (Staaterman et al. 2013). Further work should focus on determining the sources and spectrum of nocturnal fish sounds that may provide sensory cues to larval fish for recruitment (Simpson et al. 2008) and vary across reef habitats and diel periods (Radford et al. 2014).

\section{Future passive acoustic monitoring}

The ability to distinguish sounds to the levels of species and behavior confirms the potential value for acoustic monitoring of reproductive activities of target species on Hawaiian reefs. For example, sounds produced by the male Hawaiian dascyllus Dascyllus albisella can be used in conjunction with acoustic monitoring to demonstrate the correlation between rates of sound production and spawning season (Mann \& Lobel 1995, Lammers et al. 2008). Our records of sounds produced during courtship, spawning, and nest defense indicate this potential application to at least 20 other species of Hawaiian reef fish (Fig. 1). Species such as the yellow tang, Moorish idol, butterflyfishes, and angelfishes are important to the aquarium trade (Tissot \& Hallacher 2003), and we have shown that many species produce sounds during reproductive activities. In addition, the acoustic behavior of the peacock grouper $C$. argus may be used to monitor the activity of this invasive and often ciguatoxic species for management over wide spatial areas (Dierking \& Campora 2009). On a broader scale, monitoring the production of fish sounds over long periods of time may be used to assess populations and fishing impacts on reef fishes of management concern in Hawai'i (Williams et al. 2008). Fur- 
thermore, bioacoustic recordings can be combined with other observations such as reproductive behaviors, gonad condition, spawned zygotes, lunar cycles, visual cenuses, and fish movement patterns to provide estimates of species' reproductive activity or abundance (e. g. Saucier \& Baltz 1993, Gilmore 2003, Mann et al. 2009, Rowell et al. 2012). Thus the use of fish sound libraries is of future value to estimate the population activities and abundances of threatened, endangered, and other species of concern to managers. We are currently using these species-specific behavior sounds as acoustic templates to identify periodic population behaviors across several years of continuous passive acoustic recordings in our Hawaiian study reef communities.

Acknowledgements. This research was funded by a grant from NOAA's Undersea Research Program and Coral Reef Conservation Program, and the Hawai'i Undersea Research Laboratory under NOAA award NA05OAR4301108. We thank John Smith and Chris Kelly from HURL for facilitating this research project. We thank Dave Pence, UH Diving Safety Officer, and the DSO staff for their rebreather training and diving operations advice and support. We thank Les Wilson, UH Department of Mathematics, for providing student support as part of his Interdisciplinary Training and Research for Math and Biology Undergraduates funded by the National Science Foundation grant DUE06-34624 Undergraduate Biology and Mathematics Program. From that student group we thank undergraduate students Geraldine Cadalin, Mary Desjardins, Atma Bhawuk, and Michael Andonian for their assistance in video and acoustic data extraction and analyses. John Allen, Mark Lammers, and Polyanna Fisher provided many helpful suggestions on the analysis of fish sounds. The anonymous reviewers are acknowledged for their helpful suggestions and comments on this manuscript. This is contribution number 1598 from the Hawai'i Institute of Marine Biology.

\section{LITERATURE CITED}

Allen GR, Werner TB (2002) Coral reef fish assessment in the 'Coral Triangle' of southeastern Asia. Environ Biol Fishes 65:209-214

> Anderson KA, Rountree RA, Juanes F (2008) Soniferous fishes in the Hudson River. Trans Am Fish Soc 137: 616-626

Bellwood DR, Wainwright PC (2002) The history and biogeography of fishes on coral reefs. In: Sale PF (ed) Coral reef fishes. Dynamics and diversity in a complex ecosystem. Academic Press, San Diego, CA, p 5-32

Boyle KS, Cox TE (2009) Courtship and spawning sounds in bird wrasse Gomphosus varius and saddle wrasse Thalassoma duperrey. J Fish Biol 75:2670-2681

> Boyle KS, Tricas TC (2010) Pulse sound generation, anterior swim bladder buckling, and associated muscle activity in the pyramid butterflyfish, Hemitaurichthys polylepis. J Exp Biol 213:3881-3893

Boyle KS, Tricas TC (2011) Sound production in the long- nose butterflyfishes (genus Forcipiger): cranial kinematics, muscle activity and honest signals. J Exp Biol 214:3829-3842

Bright TJ (1972) Bio-acoustic studies on reef organisms. In: Collette BB, Earle SA (eds) Results of the Tektite program: ecology of coral reef fishes. Bull Los Angel Nat Hist Mus 14:45-70

Cato DH (1978) Marine biological choruses observed in tropical waters near Australia. J Acoust Soc Am 64:736-743

> Cato DH (1980) Some unusual sounds of apparent biological origin responsible for sustained background noise in the Timor Sea. J Acoust Soc Am 68:1056-1060

Cummings WC, Brahy BD, Herrnkind WF (1964) The occurrence of underwater sounds of biological origin off the west coast of Bimini, Bahamas. In: Tavolga WN (ed) Marine bio-acoustics. Pergamon, New York, NY, p 27-43

Cummings WC, Brahy BD, Spires JY (1966) Sound production, schooling, and feeding habits of the margate, Haemulon album Cuvier, off North Bimini, Bahamas. Bull Mar Sci 16:626-640

Dierking J, Campora CE (2009) Ciguatera in the introduced fish Cephalopholis argus (Serranidae) in Hawai'i and implications for fishery management. Pac Sci 63:193-204

Fine ML, Winn HE, Olla BL (1977) Communication in fishes. In: Sebeok TA (ed) How animals communicate. Indiana University Press, Bloomington, IN, p 472-518

Fish MP, Mowbray WH (1970) Sounds of western North Atlantic fishes. Johns Hopkins Press, Baltimore, MD

Gilmore RG Jr (2003) Sound production and communication in the spotted seatrout. In: Bortone SA (ed) Biology of the spotted seatrout. CRC Press, Boca Raton, FL, p 177-195

> Horch K, Salmon M (1973) Adaptations to the acoustic environment by the squirrelfishes Myripristis violaceus and M. pralinius. Mar Behav Physiol 2:121-139

Kumpf HE (1964) Use of underwater television in bioacoustic research. In: Tavolga WN (ed) Marine bioacoustics. Pergamon, New York, NY, p 47-57

> Ladich F (1997) Agonistic behavior and significance of sounds in vocalizing fish. Mar Freshw Behav Physiol 29: 87-108

> Lammers MO, Brainard RE, Au WWL, Mooney A, Wong K (2008) An ecological acoustic recorder (EAR) for longterm monitoring of biological and anthropogenic sounds on coral reefs and other marine habitats. J Acoust Soc Am 123:1720-1728

> Lobel PS (1992) Sounds produced by spawning fish. Environ Biol Fishes 33:351-358

Lobel PS (1996) Spawning sound of the trunkfish, Ostracion meleagris (Ostraciidae). Biol Bull (Woods Hole) 191: 308-309

Lobel PS (2005) Scuba bubble noise and fish behavior: a rationale for silent diving technology. Proceedings of the American Academy of Underwater Sciences Symposium, University of Connecticut at Avery Point, Groton, CT, p 49-59

> Lobel JM, Kerr LM (1999) Courtship sounds of the Pacific damselfish, Abudefduf sordidus (Pomacentridae). Biol Bull (Woods Hole) 197:242-244

Lobel PS, Mann DA (1995) Spawning sounds of the domino damselfish Dascyllus albisella (Pomacentridae), and the relationship to male size. Bioacoustics 6:187-198

Lobel PS, Kaatz IM, Rice AN (2010) Acoustical behavior of coral reef fishes. In: Cole KS (ed) Reproduction and sexuality in marine fishes. University of California Press, Berkeley, CA, p 307-348 
Luczkovich JJ, Mann DA, Rountree RA (2008) Passive acoustics as a tool in fisheries: an introduction to the American Fisheries Society Symposium. Trans Am Fish Soc 137:533-541

Mann DA, Jarvis SM (2004) Potential sound production by a deep-sea fish. J Acoust Soc Am 115:2331-2333

Mann DA, Lobel PS (1995) Passive acoustic detection of sounds produced by the damselfish, Dascyllus albisella (Pomacentridae). Bioacoustics 6:199-213

> Mann DA, Lobel PS (1998) Acoustic behavior of the damselfish Dascyllus albisella: behavioral and geographic variation. Environ Biol Fishes 51:421-428

Mann DA, Locascio JV, Coleman FC, Koenig CC (2009) Goliath grouper Epinephelus itajara sound production and movement patterns on aggregation sites. Endang Species Res 7:229-236

Maruska KP, Boyle KS, Dewan LR, Tricas TC (2007) Sound production and spectral hearing sensitivity in the Hawaiian sergeant damselfish, Abudefduf abdominalis. J Exp Biol 210:3990-4004

McCauley RD, Cato DH (2000) Patterns of fish calling in a nearshore environment in the Great Barrier Reef. Philos Trans R Soc Lond B Biol Sci 355:1289-1293

Moulton JM (1958) The acoustical behavior of some fishes in the Bimini area. Biol Bull (Woods Hole) 114:357-374

Myrberg AA (1980) Ocean noise and the behavior of marine animals: relationships and implications. In: Diemer FP, Vernberg JF, Mirkes DZ (eds) Advanced concepts in ocean measurements for marine biology. University of South Carolina Press, Columbia, SC, p 461-491

Myrberg AA (1981) Sound communication and interception in fishes. In: Tavolga W, Popper AN, Fay RR (eds) Hearing and sound communication in fishes. Springer-Verlag, New York, NY, p 395-426

Myrberg AA Jr, Fuiman LA (2002) The sensory world of coral reef fishes. In: Sale PF (ed) Coral reef fishes: dynamics and diversity in a complex ecosystem. Elsevier Academic Press, San Diego, CA, p 123-148

Radford CA, Jeffs AG, Tindle CT, Cole RG, Montgomery JC (2005) Bubbled waters: the noise generated by underwater breathing apparatus. Mar Freshw Behav Physiol 38:259-267

Radford CA, Stanley JA, Jeffs AG (2014) Adjacent coral reef habitats produce different underwater sound signatures. Mar Ecol Prog Ser 505:19-28

Randall JE (2007) Reef and shore fishes of the Hawaiian Islands. Sea Grant College Program, University of Hawaii, Honolulu, HI

Rountree RA, Goudey C, Hawkins T, Luczkovich J, Mann D (2003a) Listening to fish: passive acoustic applications in marine fisheries. Sea Grant Digital Oceans. Massachusetts Institute of Technology Sea Grant College Program. MITSG 0301, Cambridge, MA

Rountree RA, Goudey C, Hawkins T (2003b) Listening to fish: proceedings of the international workshop on the applications of passive acoustics to fisheries, 8-10 April 2002, Dedham, MA. MIT Sea Grant Technical Report

Editorial responsibility: Ivan Nagelkerken,

Adelaide, South Australia, Australia
MITSG 03-2, Cambridge, MA

Rountree RA, Gilmore RG, Goudey CA, Hawkins AD, Luczkovich J, Mann D (2006) Listening to fish: applications of passive acoustics to fisheries science. Fisheries 31:433-446

Rowell TJ, Schärer MT, Appeldoorn RS, Nemeth MI, Mann DA, Rivera JA (2012) Sound production as an indicator of red hind density at a spawning aggregation. Mar Ecol Prog Ser 462:241-250

Salmon M (1967) Acoustical behavior of the mempachi, Myripristis berndti, in Hawaii. Pac Sci 21:364-381

> Salmon M, Winn HE (1966) Sound production by priacanthid fishes. Copeia 1966:869-872

Salmon M, Winn HE, Sorgente N (1968) Sound production and acoustical behavior in triggerfish. Pac Sci 12:11-20

Sartori JD, Bright TJ (1973) Hydrophonic study of the feeding activities of certain Bahamian parrotfishes, family Scaridae. Hydro-Lab J 2:25-56

Saucier MH, Baltz DM (1993) Spawning site selection by spotted seatrout, Cynoscion nebulosus, and black drum, Pogonias cromis, in Louisiana. Environ Biol Fishes 36:257-272

Simpson SD, Meekan MG, Jeffs A, Montgomery JC, McCauley RD (2008) Settlement-stage coral reef fish prefer the higher-frequency invertebrate-generated audible component of reef noise. Anim Behav 75:1861-1868

Sprague MW, Luczkovich JJ (2001) Do striped cusk-eels Ophidion marginatum (Ophidiidae) produce the 'chatter' sound attributed to weakfish Cynoscion regalis (Sciaenidae)? Copeia 2001:854-859

Staaterman E, Rice AN, Mann DA, Paris CB (2013) Soundscapes from a tropical eastern Pacific reef and a Caribbean Sea reef. Coral Reefs 32:553-557

> Steinberg JC, Kronengold M, Cummings WC (1962) Hydrophone installation for the study of soniferous marine animals. J Acoust Soc Am 34:1090-1095

Steinberg JC, Cummings WC, Brahy BD, MacBain (Spires) JY (1965) Further bioacoustic studies off the west coast of North Bimini, Bahamas. Bull Mar Sci 15:942-963

Tissot BN, Hallacher LE (2003) Effects of aquarium collectors on coral reef fishes in Kona, Hawaii. Conserv Biol 17: 1759-1768

> Tricas TC, Kajiura SM, Kosaki R (2006) Acoustic communication in territorial butterflyfish: test of the sound production hypothesis. J Exp Biol 209:4994-5004

Urick RJ (1983) Principles of underwater sound. McGrawHill, New York, NY

Wenz GM (1962) Acoustic ambient noise in the ocean: spectra and sources. J Acoust Soc Am 34:1936-1956

Williams ID, Walsh WJ, Schroeder RE, Friedlander AM, Richards BL, Stamoulis KA (2008) Assessing the importance of fishing impacts on Hawaiian coral reef fish assemblages along regional-scale human population gradients. Environ Conserv 35:261-272

Winn HE, Marshall JD, Hazlett B (1964) Behavior, diel activities, and stimuli that elicit sound production, and reaction to sounds in the longspine squirrelfish. Copeia 1964: 413-425

Submitted: February 17, 2014; Accepted: June 26, 2014 Proofs received from author(s): August 28, 2014 